\title{
e-Journal in Radiology - a timely step in sharing knowledge
}

From Dr (Mrs) Gulpa Subasinghe

Head, Department of Imaging and Diagnostics, The Central Hospital

Editors,

The American poet and author Robin Morgan, in her compilation "Sisterhood is Powerful", rated as one of the 100 most influential books of the $20^{\text {th }}$ Century, says "Knowledge is power. Information is power. The secreting or hoarding of knowledge or information may be an act of tyranny". This no doubt is applicable to all fields of learning, medical education being no exception!

The knowledge we acquire may be used competitively or cooperatively, the former treating knowledge as a mechanism of achieving an advantage over others while the latter treating knowledge as something to be shared and pursued. Fortunately in Sri Lanka the fraternity of radiologists has already taken some very positive initiatives to share knowledge by way of conducting regular meetings, conferences, seminars, workshops etc. However, I personally feel that we need to do more.

Our pool of nearly 140 or so radiologists spread over 100 stations island wide, daily handles several thousand cases. This pool of clinical information can be turned to a gold mine of knowledge if, even a fraction of this information is properly analyzed and disseminated. According to Einstein "Information is not knowledge. The only source of knowledge is experience." So it is important for us to ensure that our fellow radiologists experience our experiences, more so as beneficiaries of free education, taking inspiration from the ancient proverb "teaching others we teach ourselves".

Over the years the calendar of events of the college of Radiology has shown an impressive growth strengthening the process of sharing knowledge and experiences among the membership. Publication of the Journal of Radiology few years back was a very positive development in this respect. I wish to congratulate the College for moving with the times by publishing an e-journal, helping the members to share information with speed and more efficiently and with convenience. However, we should strive to upgrade the quality of knowledge we share through the journal, not mere information, if we were to make the journal achieve its goals. I wish the Journal all the success.

A candle loses nothing by lighting another candle - James Keller 